\title{
GESTAÇÃO, PUERPÉRIO E A INFLUÊNCIA DOS AVÓS LONGEVOS
}

\author{
Manoelle Miollo Vieira ${ }^{1}$; Gabriélly Alves Severo²; Mariana Seidel${ }^{3}$; Maria Helena \\ Gehlen ${ }^{4}$.
}

\section{RESUMO}

O estudo tem como objetivo expor e informar sobre a influência dos avós na gestação e puerpério, com enfoque em um Instituto de Longa Permanência para Idosos, situado em um municipio no Rio Grande do Sul. Trata-se de um relato de experiência construído na disciplina de Atenção Integral à Saúde do Idoso com público-alvo as idosas da ILPI. Foi desenvolvido por acadêmicas de enfermagem uma ação com 10 idosas do lar, como mediadora da ação as funcionárias do local realizaram a atividade proposta. O resultado da ação foi gravado e fotografado, com autorização, com objetivo de compartilhar o conhecimento destas idosas e a sua influência. Como conclusão destaca-se a importância de incluir os idosos nas consultas de pré-natal e puerpério entendendo que estes têm a intenção de ajudar.

Palavras-chave: : Educação; pré-natal; pessoa idosa.

Eixo Temático: Atenção Integral e Promoção á Saúde (AIPS).

\section{INTRODUÇÃO}

Quando se pensa no envelhecimento, logo vem à mente o carinho dos avós, o colo aconchegante e acolhedor, a sua fisionomia, a pele fofinha e enrugada, seus cabelos brancos. Estas e outras particularidades perceptíveis nos longevos são consideradas o início do processo do envelhecimento. Para Civinski, Montibeller e De Oliveira (2011), o processo de envelhecimento é caracterizado por constantes mudanças morfológicas, bioquímicas, psicológicas e fisiológicas que acontecem no

\footnotetext{
${ }^{1}$ Acadêmica de enfermagem - Manoelle Miollo Vieira - Universidade Franciscana. E-mail: m.miollo@ufn.edu.br

${ }^{2}$ Acadêmica de enfermagem - Gabriélly Alves Severo - Universidade Franciscana. E-mail: gabrielly.severo@ufn.edu.br

${ }^{3}$ Acadêmica de enfermagem: Mariana Seidel - Universidade Franciscana. E-mail: mariana.seidel@ufn.edu.br

${ }^{4}$ Orientadora: Professora Dra. Maria Helena Ghelen - Universidade Franciscana. E-mail: mah@ufn.edu.br
} 
organismo o tempo todo. E para nortear esse olhar direcionando o conhecimento tem-se os dados disponibilizados pelo Instituto Brasileiro de Geografia e Estatística IBGE 2010, onde é considerada uma pessoa idosa quem tem 60 anos de idade ou mais.

Pessoas idosas já trilharam uma longa trajetória na vida e adquiriram muitas experiências, as quais podem ser compartilhadas. Essas vivências podem contribuir para auxiliar jovens mães com seus filhos, durante a gestação e até mesmo mães no processo de puerpério, com dicas e conselhos, visto que durante este período de gestação e maternidade, os avós se fazem presente. Algumas gestantes ficam inseguras com o novo momento, e as avós sentem a necessidade de estar perto amparando suas filhas ou noras, fazendo parte deste momento especial. A importância do cuidado de avó-neto, mãe-filha refaz na memória da idosa seus momentos e experiências como mãe, reviver o momento do primeiro banho, a primeira troca de fraldas e a pega para amamentar, reviver seu parto (ZANIN E SCHACKER, 2010).

De acordo com Rakelly e Bezerra (2012), às mães têm convicção nos ensinamentos passados pelas avós, chás para tratamento de asma, resfriado, pneumonia, e até mesmo nas tradições religiosas. O conhecimento dessas longevas vem passando de geração em geração, a conhecida medicina popular, muito eficaz, elas auxiliam as mães de "primeira viagem" nesse novo mundo desconhecido da maternidade, em que elas são pioneiras experientes.

A convivência de netos com avós auxilia na construção do papel do idoso na família e sua inserção nas atividades diárias. Resultando em um relacionamento leve onde as avós se tornam conselheiras, amigas, historiadoras, transmitem proteção e parceria a seus netos. De tal modo os longevos e idosos sentem-se mais ativos e consequentemente cuidam de sua saúde para seguir no acompanhamento da criança (LOUZEIRO E LIMA, 2017).

O principal objetivo desta avaliação é ampliar a percepção teórico e prática da visibilidade dos longevos no período gestacional e puerperal, com vistas ao desenvolvimento crítico-reflexivo do profissional de Enfermagem. 


\section{METODOLOGIA}

Trata-se de um relato de experiência, realizado a partir de uma ação extensionista desenvolvida no Instituto de Longa Permanência para Idosos (ILPI) localizado em um município do Rio Grande do Sul, durante a aprendizagem na disciplina de Atenção Integral à Saúde do Idoso, no primeiro semestre de 2021.

Para o desenvolvimento da extensão foi realizado sorteio da temática durante as aulas remotas, e definido as temáticas por meio do diagnóstico situacional. De tal modo, a ação foi desenvolvida com 10 mulheres longevas, moradoras do lar, com o auxílio e mediação da funcionária do local, uma profissional psicóloga, realizando a comunicação entre as acadêmicas e as longevas para a ação.

Deste modo, na plataforma Google Meet foram realizadas reuniões online com o grupo, sendo elaboradas questões para que as longevas respondessem através de um vídeo e registro de fotos, com ajuda dos profissionais do local. A questão elaborada tem o intuito de mostrar a sua conduta com um recém nascido e conselhos para gestantes.

As perguntas elaboradas e escolhidas foram: Qual seu conselho para as gestantes de hoje? O que não pode fazer durante a gestação? Quais os cuidados indispensáveis durante a gestação? O que não pode faltar na minha bolsa maternidade? Quando bebe está com soluço, o que fazer? O que fazer quando o bebe tem cólica? Quantas vezes devo dar banho em um recém nascido? Como ver a temperatura da água na hora do banho? Como realizar o desfralde? Como que faz uma "mama"?

As respostas das Longevas serviram como base para afirmar o estudo. Deste modo será apresentado a importância do convívio dos longevos para o bem estar do RN, mãe e avó, ou seja, da família.

\section{RESULTADOS E DISCUSSÕES}

Para uma educação em saúde qualificada na realidade de gestantes e puérperas é preciso ampliar o pré-natal para as acompanhantes idosas que se farão presentes na educação do recém nascido. Algumas perguntas foram selecionadas 
através das respostas colhidas e percebe-se que as idosas têm muito a contribuir para puérperas e gestantes, com dedicação, amor e cuidado. Ao levar esta ação até - lar pôde perceber através do vídeo a felicidade delas por contribuírem com seu conhecimento, confirmando a importancia da inclusão.

Percebeu-se que a influência das avós na gestação se configurava como algo a ser seguido de olhos fechados, e hoje em dia com atualização e educação em saúde ampliada as gestantes estão buscando conhecimento fora do ambiente familiar. Ainda existem pais que confiam de olhos fechados nas orientações dos avós, reforçando a importância do pré-natal juntamente com idosos que se farão presentes nos cuidados do recém nascido (ZANIN E SCHACKER, 2010).

Para o idoso há uma dificuldade em aceitar certas limitações e a troca de responsabilidades; onde antes o idoso era o provedor e responsável do lar. Quando os papéis são invertidos, vem o sentimento de incapacidade, impotência, sem motivações por não ter mais compromissos ou responsabilidades que passam a ser supridas pelos filhos ou netos (BRASIL, 2006).

É importante que haja inclusão dos idosos nas atividades diárias do lar, de acordo com sua autonomia e disposição. A nova rotina com o recém nascido auxilia na saúde mental, fazendo este idoso sentir-se útil no ambiente em que convive, estimulando seu bem estar, senso de cognição, pinça e marcha, promovendo saúde e evitando que os riscos de fragilidade aumentem (LOUZEIRO E LIMA, 2017).

As técnicas e procedimentos de saúde mudaram ao longo dos anos, atualmente não é permitido o uso de chás e água antes dos 6 meses de vida. Uma pessoa idosa ainda está habituada com orientações desatualizadas frente aos cuidados com recém nascido, mas a presença do idoso não deixa de ser importante para a mãe e o RN (GREGÓRIO E PADILHA, 2012).

Em conformidade um recém nascido/membro novo da família é motivo de alegria e esperança, a vivência de uma nova rotina traz motivação ao idoso quando inserido nas atividades do RN. A inclusão nas tarefas é fundamental para que o idoso se sinta útil e importante na família, podendo ser ofertadas atividades de 
compromisso como: cuidar dos horários para amamentação, escolher a roupinha, fazer a soneca da tarde e até mesmo dar alimentos (LOUZEIRO E LIMA, 2017).

\section{CONCLUSÃO}

Ao descrever o desenvolvimento da ação extensionista nos proporcionou também a vivência da interprofissionalidade, o que nos permite considerar a importância de inserir os idosos nas consultas do puerpério, e assegurando às puérperas a entender que estes idosos têm a intenção de ajudar. Também de que a estimulação do convívio entre o idoso e seu neto reforça a vontade do autocuidado, sentindo a necessidade de transmitir bom exemplo à criança, ao querer acompanhar o crescimento do neto o idoso passa a buscar uma qualidade de vida melhor.

Contudo, a experiência vivenciada na ação com o instituto de longa permanência, lar das vovozinhas, foi enriquecedora para os acadêmicos de enfermagem em formação, pois foi possível analisar os diferentes saberes, refletir as diferentes formas de abordar pessoas longevas com pensamento antigos relacionado aos cuidados com $\mathrm{RN}$, e como inserir essa longeva neste período.

\section{AGRADECIMENTOS}

Ao evento pela oportunidade, a professora pela disponibilidade e as colegas.

\section{REFERÊNCIAS}

BRASIL. Ministério da Saúde. Cadernos de atenção básica - n.ำ19. Envelhecimento e saúde da pessoa idosa. Brasília - DF, 2006. Disponível em: http://189.28.128.100/dab/docs/publicacoes/cadernos ab/abcad19.pdf

CIVINSKI, C; MONTIBELLER, A; DE OLIVEIRA, A.L. A importância do exercício físico no envelhecimento. Revista da UNIFEBE, v. 1, n. 09, 2011. Disponível em: https://periodicos.unifebe.edu.br/index.php/revistaeletronicadaunifebe/article/view/68/ 57\#

GREGÓRIO. V, R,P; PADILHA.M,I. História do cuidado ao recém-nascido na Maternidade Carmela Dutra - Florianópolis-SC/Brasil (1956-2001). Escola Anna Nery [online]. 2012, v. 16, n. 2 , pp. 354-362. Disponível em: https://doi.org/10.1590/S1414-81452012000200021 
IBGE - Instituto Brasileiro de Geografia e Estatística. Idosos indicam caminhos para

uma melhor idade. Revista retratos. 2012 Disponível em:

https://agenciadenoticias.ibge.gov.br/agencia-noticias/2012-agencia-de-

noticias/noticias/24036-idosos-indicam-caminhos-para-uma-melhor-idade

LOUZEIRO, C.F.A ; LIMA, A. B.R. Família e Envelhecimento: um estudo sobre as relações entre avós e netos. Revista Ceuma Perspectivas, vol. 30, 2017. Disponível

em:

http://www.ceuma.br/portalderevistas/index.php/RCCP/article/view/108/pdf acesso em: 20 de abril, 2021.

RAKELLY. D,O; BEZERRA. G,D. Práticas culturais de cuidados entre mães de lactentes com infecção respiratória. Revista Brasileira em Promoção da Saúde, vol. 25, núm. 2, abril-junio, 2012, pp. 13-19. Fortaleza-Ceará, Brasil. DISPONÍVEL EM: https://www.redalyc.org/pdf/408/40823252004.pdf acesso em: 18 de abril, 2021.

ZANIN. L,C; SCHACKER. L,C. Avós Maternas: Incentivadoras da amamentação? Revista Conhecimento Online - Ano 2 - Vol. 1 - março de 2010. Disponível em: https://periodicos.feevale.br/seer/index.php/revistaconhecimentoonline/article/view/1 32/1649 acesso em: 20 de Abril, 2021. 